\title{
IL-17A in the Psoriatic Patients' Serum and Plaque Scales as Potential Marker of the Diseases Severity and Obesity
}

\author{
Anna Michalak-Stoma $\left(\mathbb{D},{ }^{1}\right.$ Joanna Bartosińska $\left(\mathbb{D},{ }^{1}\right.$ Małgorzata Kowal $\left(\mathbb{D},{ }^{1}\right.$ \\ Dorota Raczkiewicz $\mathbb{D}^{2},{ }^{2}$ Dorota Krasowska ${ }^{(D},{ }^{1}$ and Grażyna Chodorowska ${ }^{1}{ }^{1}$ \\ ${ }^{1}$ Chair and Department of Dermatology, Venereology and Pediatric Dermatology, Medical University of Lublin, ul. Staszica 16, \\ 20-081 Lublin, Poland \\ ${ }^{2}$ Institute of Statistics and Demography, Warsaw School of Economics, al. Niepodległości 162, 02-554 Warsaw, Poland
}

Correspondence should be addressed to Anna Michalak-Stoma; annamichalak@wp.pl

Received 2 March 2020; Accepted 19 May 2020; Published 5 June 2020

Academic Editor: Michele T. Pritchard

Copyright (C) 2020 Anna Michalak-Stoma et al. This is an open access article distributed under the Creative Commons Attribution License, which permits unrestricted use, distribution, and reproduction in any medium, provided the original work is properly cited.

\begin{abstract}
The aim of the study was to evaluate concentrations of IL-17 in the serum and plaque scales of psoriatic patients. We analyzed their association with the clinical activity of the disease and with body mass index (BMI). Demographic data, medical history, serum, and scale from psoriatic plaques for assessment of IL-17 were collected from all the participants. The disease severity was assessed with PASI (Psoriasis Area and Severity Index), BSA (Body Surface Area), PGA (Physician Global Assessment), NAPSI (Nail Psoriasis Severity Index), and DLQI (Dermatology Quality of Life Index) scores. Obesity was diagnosed by calculating body mass index. Serum and scale concentration of IL-17 was determined with Human IL-17A High Sensitivity ELISA kit and Human IL-17 ELISA kit. In the psoriatic patients, BMI was statistically significantly higher than in the control group. Most of the patients presented BMI higher than normal. Our study confirms that overweight is a problem among psoriatic patients. A significant positive correlation between the IL-17 serum and scale concentrations and psoriasis severity indicates that IL-17 can be used as the marker of disease severity. More data from human studies can be crucial for understanding that relationship between IL-17, psoriasis, and obesity.
\end{abstract}

\section{Introduction}

Psoriasis is a common chronic disease with the prevalence from 0.91 in the USA to $8.5 \%$ in Norway, whose new pathogenesis aspects are constantly being explored $[1,2]$. Nowadays, psoriasis can be considered as an autoimmune and autoinflammatory disorder. It is already recognized that psoriasis is not only skin specific but also a systemic disease, and many comorbidities are found as psoriasis related [3]. The common diseases among psoriatic patients are psoriatic arthritis, diabetes mellitus, hypertension, hyperlipidemia, coronary heart disease, Crohn's disease, nonalcoholic fatty liver disease, T-cell lymphoma, and depression [4]. In addition, the rate of obesity for psoriatic patients is higher as compared with controls [5].

Since 2005, when Th17, the new subtype of T helper cells was discovered, many studies are conducted to find the role of IL-17 in psoriasis and other diseases' pathogenesis [6-9]. IL-17 (IL-17A) is a member of the cytokine family comprising IL-17A, IL-17B, IL-17C, IL-17D, IL-17E (IL-25), and IL-17F. Mostly, T helper 17 (Th17) cells secrete IL-17, but also, T regulatory (Treg) cells, NK cells, mast cells, and neutrophils are engaged in IL-17 production $[10,11]$. IL17 has a proinflammatory activity inducing the expression of proinflammatory cytokines, colony-stimulating factors, and chemokines from dendritic cells, neutrophils, $T$ cells, monocyte/macrophages, and epithelial cells $[6,12,13]$. Some authors indicate the proinflammatory role of IL-17 in obesity $[7,14-16]$. In obese people, IL-6 is overproduced by adipocytes and macrophages in visceral adipose tissue [17], what influences on IL-17 production. There is a positive feedback between IL-17 and IL-6, and IL-17 stimulates IL- 6 production. On the other hand, there is evidence of the inhibitory effect of IL-17 on adipogenesis [14]. 
The aim of the study was to evaluate concentrations of IL-17 in the serum and plaque scales of psoriatic patients. We analyzed their association with the clinical activity of the disease and with body mass index (BMI).

\subsection{Clinical Significances}

(i) Psoriasis can be considered as an autoimmune and autoinflammatory disorder

(ii) The rate of obesity for psoriatic patients is higher as compared with controls

(iii) IL-17 has an important role in the pathogenesis of psoriasis

(iv) IL-17 may have a proinflammatory role in obesity

(v) There is evidence of the inhibitory effect of IL-17 on adipogenesis

(vi) Assessment of different biomarkers, for example, IL-17 in the plaque scale, can expand our knowledge about psoriasis pathophysiology

(vii) Correlations between IL-17 concentration in serum and plaque scale of psoriatic patients, and disease severity and body mass index can be helpful in understanding the mechanisms of overweight and obesity among psoriatic patients

\section{Materials and Methods}

2.1. Studied Group. The study was conducted in patients hospitalized in the Department of Dermatology, Venereology and Pediatric Dermatology, Medical University of Lublin, Poland, due to psoriasis exacerbation.

The study comprised 21 male psoriatic patients and 20 male healthy controls. Inclusion criteria were the duration of psoriasis for at least one year, the presence of active psoriatic skin lesions with scale on the skin, and age above 18 years old. Patients who received any systemic treatment for psoriasis or applied steroids, retinoids, anthralin, or vitamin D analogs on the skin within the last 2 months were excluded from the study. Patients with the presence of any disease which required continuous treatment were excluded from the study.

Demographic data, medical history, serum, and scale from psoriatic plaques for assessment of IL-17 were collected from all the participants.

The study was approved by the Local Ethics Committee at the Medical University of Lublin (KE-0254/81/2015). The written informed consent for study participation was obtained from all study subjects.

2.2. Assessment of Psoriasis Severity and Obesity. The skin changes severity was assessed with the use of PASI (Psoriasis Area and Severity Index), BSA (Body Surface Area), and PGA (Physician Global Assessment) scores. Nail involvement was assessed with Nail Psoriasis Severity Index (NAPSI). The patients filled up the Dermatology Quality of Life Index (DLQI) form.
Obesity was diagnosed by calculating body mass index (BMI), which is the weight in kilograms divided by the square of the height in meters. The World Health Organization classifies BMI in adults between 18.5 and 24.9 as normal, 25-29 as overweight, and BMI 30 and more as obesity [5].

2.3. Assessment of $I L-17$ Serum Concentrations in the Psoriatic Patients and Controls. Blood samples were collected from psoriatic patients and controls and were centrifuged for 15 minutes at $1000 \mathrm{x}$. Then, serum samples were subdivided into small aliquots to be stored at $-80^{\circ} \mathrm{C}$ until tested for cytokine levels. In the studied psoriatic patients as well as the control group, concentrations of IL17 were determined with the use of Human IL-17A High Sensitivity ELISA kit (eBioscience, Vienna, Austria), according to the manufacturer's instructions.

2.4. Assessment of IL-17 Scale Concentrations in the Psoriatic Patients. All patients were treated initially with a topical application of $5 \%$ salicylic acid ointment for desquamation. Plaque scales were collected from the most representative lesions. The same amount of scale from each patient was weighed. Then, plaque scales were suspended in phosphatebuffered saline (PBS) without calcium and magnesium and disrupted with Sonics Vibracell VCX130 in impulsing mode. Cell suspension was centrifuged for 10 minutes at $5000 \mathrm{x} \mathrm{g}$. Then, scale samples were subdivided into small aliquots to be stored at $-80^{\circ} \mathrm{C}$ until tested for cytokine levels. The concentration of IL-17 in the patient plaque scales was determined with the use of Human IL-17A High Sensitivity ELISA kit (eBioscience, Vienna, Austria) and Human IL-17 ELISA kit (R\&D Systems, Minneapolis, MN, USA), according to the manufacturers' instructions. With Human IL17A High Sensitivity ELISA kit, we have reached very high results, which were out of range. That is why we repeated the analysis with Human IL-17 ELISA kit (R\&D Systems, Minneapolis, MN, USA).

2.5. Statistical Analysis. Statistical analysis was performed using STATISTICA software. Mean values $(M)$ and standard deviations (SD) were calculated for continuous variables, or absolute numbers $(n)$ and relative numbers (\%) of occurrence of items of categorical variables. The following tests were applied: stochastic independence $\chi^{2}$, U Mann-Whitney test, $r$ Pearson correlation coefficient. In all statistical tests, the level of significance was set at 0.05 .

\section{Results}

3.1. Characteristics of the Studied Group. The characteristic of the studied groups is presented in Table 1 . In the psoriatic patients, BMI was higher $(27.32 \pm 5.3)$ than in the control group $(24.81 \pm 3.09)$, and it was a statistically significant difference $p<0.05$. Most of our patients presented BMI higher than normal: $8(38 \%)$ patients were classified as overweight (range of BMI 25.0-29.9), and 8 (38\%) patients were classified as obese (BMI above 30). Among the study group, 5 (24\%) patients had normal BMI in the range 18.5-24.9. There was not any correlation between BMI and PASI, BSA, or PGA. 
TABLE 1: Characteristics of studied groups.

\begin{tabular}{|c|c|c|c|c|c|c|c|c|}
\hline \multirow{2}{*}{ Variable } & \multicolumn{4}{|c|}{ Psoriatic patients } & \multicolumn{4}{|c|}{ Control group } \\
\hline & Min & $\operatorname{Max}$ & M & SD & Min & $\operatorname{Max}$ & M & SD \\
\hline Age (years) & 26 & 76 & 50.14 & 14.51 & 27 & 75 & 46.85 & 13.44 \\
\hline BMI & 18.8 & 46.1 & 27.32 & 5.30 & 20.68 & 30.19 & 24.81 & 3.09 \\
\hline Age of psoriasis onset (years) & 1 & 71 & 29.29 & 17.37 & & & & \\
\hline Duration of psoriasis (years) & 5 & 44 & 20.86 & 12.82 & & & & \\
\hline PASI & 10 & 47 & 24.52 & 10.36 & & & & \\
\hline PGA & 3 & 5 & 3.76 & 0.89 & & & & \\
\hline BSA $(\%)$ & 13 & 90 & 42.6 & 25.29 & & & & \\
\hline NAPSI & 0 & 80 & 23.43 & 19.82 & & & & \\
\hline DLQI & 6 & 30 & 18.62 & 7.76 & & & & \\
\hline Il-17 serum concentration & 0.54 & 11.23 & 4.24 & 3.69 & 1.21 & 6.23 & 3.06 & 1.19 \\
\hline IL-17 scale concentration & 14.74 & 181.57 & 68.32 & 51.68 & & & & \\
\hline
\end{tabular}

3.2. Serum and Scale Concentration of $I L-17$. Although serum IL-17 concentrations in psoriatic patients $(4.24 \pm 3.69 \mathrm{pg} / \mathrm{ml})$ were higher than in the control group $(3.06 \pm 1.19 \mathrm{pg} / \mathrm{ml})$, no significant differences were found $(p>0.05)$. The higher level of IL-17 was detected in scale from psoriatic plaques $(68.32 \pm 51.68 \mathrm{pg} / \mathrm{ml})$ comparing to IL-17 serum level $(4.24 \pm 3.69 \mathrm{pg} / \mathrm{ml})$. The relationship between the IL-17 serum and scale concentration was not statistically significant $(r=0.410, p=0.065)$. A significant positive correlation between the IL-17 serum concentrations and psoriasis severity measured by the PASI $(r=0.61 ; p<0.05)$, BSA $(r=0.608$; $p<0.05)$, and PGA $(r=0.542 ; p<0.05)$ was detected. A significant positive correlation between the IL-17 scale concentrations and psoriasis severity measured by BSA $(r=0.436$; $p<0.05)$ was observed. In patients with higher BMI, the scale concentration of IL-17A was decreased $(r=-0.482$; $p=0.028)$. There were no statistical correlations between BMI and IL-17 serum level in psoriatic patient $(r=-0.186$, $p=0.435)$ as well as in the control group $(r=0.213, p=$ $0.367)$.

All the correlations are presented in Table 2 and on the dot graphs (Figures 1 and 2).

\section{Discussion}

IL-17A is a very important cytokine in sustaining inflammation in psoriatic plaques. It influences the recruitment of inflammatory cells, enhances keratinocyte proliferation, and inhibits keratinocyte differentiation [18]. IL-17A is undetectable in normal skin; however, it was detected in skin lesions in allergic contact dermatitis and psoriasis vulgaris $[9,19-27]$.

Statistically significant differences in serum IL-17A level have been found in psoriatic patients comparing to healthy controls in some studies [28-33]. We found that serum IL17A level was slightly higher in psoriatic patients than controls, although the result was not significant. Arican et al. and Choe et al. presented similar results [34, 35]. Choe et al. compared IL-17A serum level in two groups: the eruptive inflammatory (EI) group, included patients with quickly spreading guttate morphology and onset or reactivation of
TABle 2: The correlation between IL-17 serum, scale concentration and clinical features and disease severity in psoriatic patients; $*$ statistically significant correlation.

\begin{tabular}{lcccc}
\hline \multirow{2}{*}{ Variable } & \multicolumn{2}{c}{$\begin{array}{c}\text { IL-17 serum } \\
\text { concentration }\end{array}$} & \multicolumn{2}{c}{$\begin{array}{c}\text { IL-17 scale } \\
\text { concentration }\end{array}$} \\
& $r$ & $p$ & $r$ & $p$ \\
\hline Age & -0.413 & 0.063 & -0.266 & 0.243 \\
Age of psoriatic onset & -0.420 & 0.058 & -0.064 & 0.782 \\
Duration of psoriasis & 0.103 & 0.657 & -0.214 & 0.351 \\
BMI & -0.186 & 0.435 & $-0.482 *$ & $0.028 *$ \\
PASI & $0.610 *$ & $0.003 *$ & 0.316 & 0.163 \\
PGA & $0.542 *$ & $0.011 *$ & 0.256 & 0.263 \\
BSA & $0.608 *$ & $0.003 *$ & $0.436 *$ & $0.048 *$ \\
DLQI & $0.503 *$ & $0.020 *$ & 0.165 & 0.476 \\
NAPSI & 0.297 & 0.191 & 0.245 & 0.284 \\
\hline
\end{tabular}

lesions shorter than 4 weeks, and the chronic stable (CS) group, included patients with large plaque morphology, an onset longer than 6 months and a stable clinical course of longer than 1 month. IL-17A showed higher levels in the EI group. Authors suggested that IL-17A is associated with EI psoriasis that has a recent onset, is quickly spreading, shows guttate morphology, and is often associated with severe pruritus and pustule formation [35]. Our patients had severe psoriasis with PASI from 10 to 47 lasting longer than 5 years. It could be the reason why IL-17A serum level was not significantly higher in psoriatic patients comparing to the control group.

Kyriakou et al. found that the median serum levels of IL17 presented no significant difference between psoriatic patients with and without nail involvement. Target NAPSI score was not significantly correlated with the serum levels of IL-17 [36]. We did not observe a significant correlation between serum level of IL-17A and NAPSI either.

In our study, IL-17A serum levels correlated with PASI, BSA, and PGA. Other authors observed correlations of IL$17 \mathrm{~A}$ with psoriasis severity [28, 33-35]. However, this correlation was not found in some papers [30]. Choe et al. noticed 


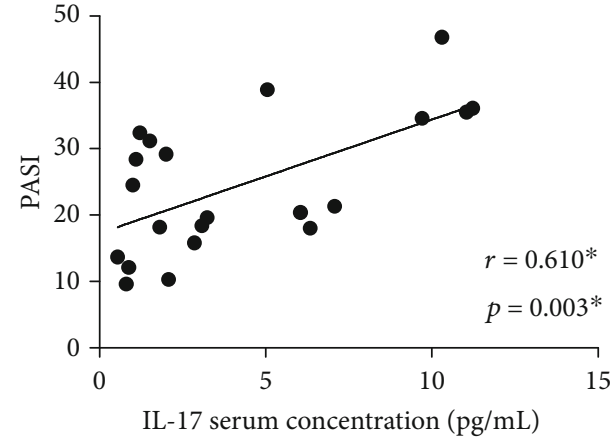

(a)

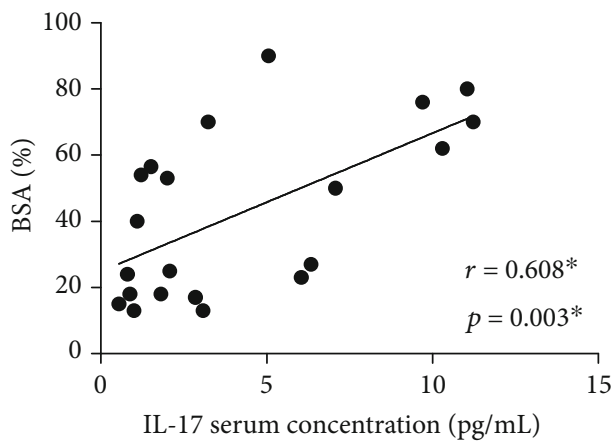

(c)

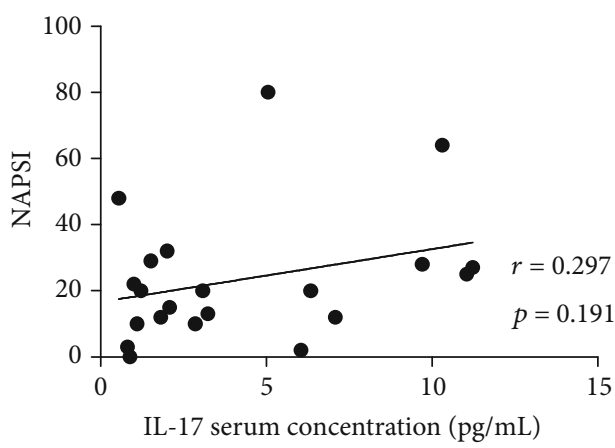

(e)

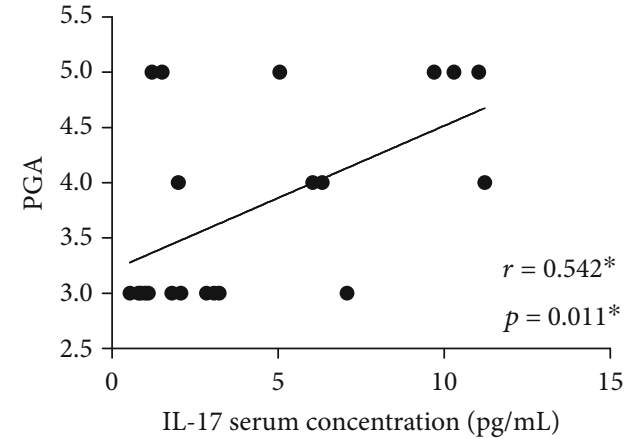

(b)

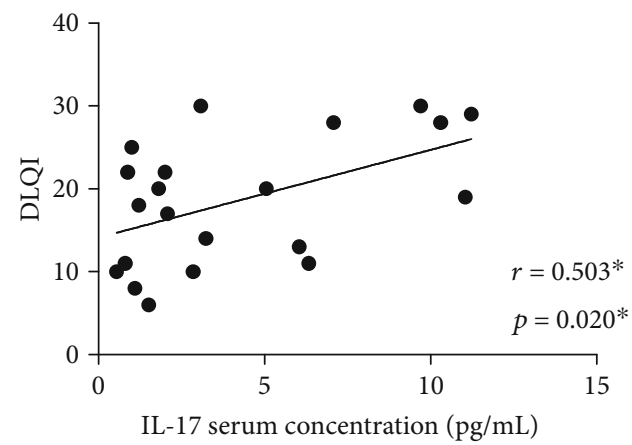

(d)

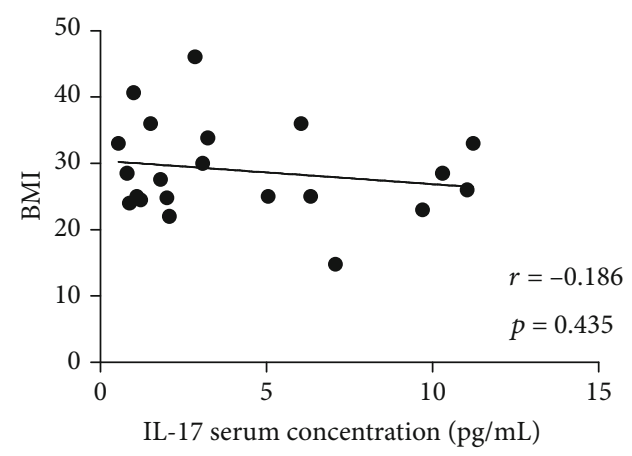

(f)

Figure 1: The correlation between IL-17 serum concentration and clinical features and disease severity in psoriatic patients; * statistically significant correlation.

a linear correlation between serum cytokine level of IL-17A and the PASI in the CS group. In the IE group, the correlation was not observed [35].

In the PubMed database, we found a few studies which have been conducted to evaluate and compare the levels of epidermal growth factor (EGF) and the soluble EGF receptor, vascular endothelial growth factor (VEGF), interleukin 18 (IL-18), transforming growth factor beta1 (TGF-beta1), IL4, IL-6, IL-10, IL-13, IL-1beta, IL-1ra, IP-10, MCP-1, MIP1alpha, MIP-1beta, PDGF, and TNF-alpha in the serum and plaque scales of psoriatic patients [37-40]. However, to our knowledge, no study has ever been conducted to assess and compare the serum level of IL-17A in serum and plaque scale in psoriatic patients. In our study, the correlation between the IL-17 serum and scale concentration was not statistically significant. However, the level of IL-17 was higher in plaque scale than in serum. This can approve the local involvement of IL-17 in psoriatic plaque and scale formation. It was found that in the psoriatic lesions not only Th17 cells but also neutrophils and mast cells can produce IL-17 [41-44], which is why the level of IL-17 in the skin can be higher than in serum. Anti-IL-17 therapy is a very effective therapy, and it was observed that neutrophilderived IL-17 is an early target of IL-17-directed therapies such as secukinumab [45]. A significant positive correlation between the IL-17 scale concentrations and psoriasis severity measured by BSA was observed. Our observations suggest that the concentration measurement of some cytokines, involved in the process of psoriatic lesion formation, can be performed in the psoriatic scale that is easy to obtain from patients.

Most of our patients were classified as overweight (38\%) patients or as obese (38\%) patients. There were not any correlations between BMI and PASI, BSA, or PGA. Our data are 


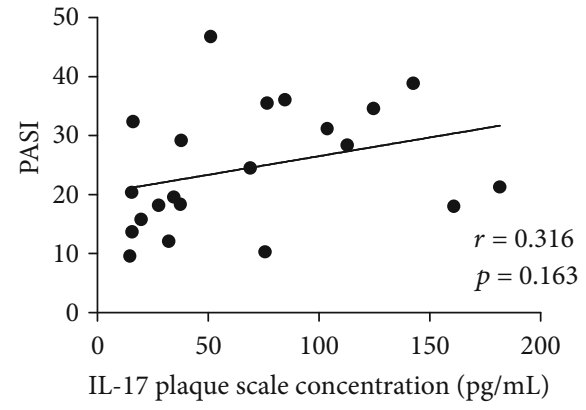

(a)

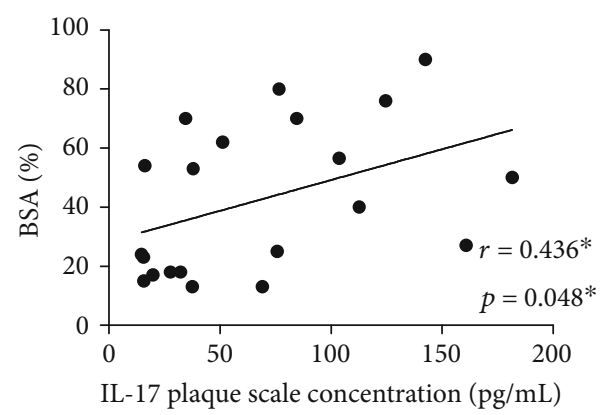

(c)

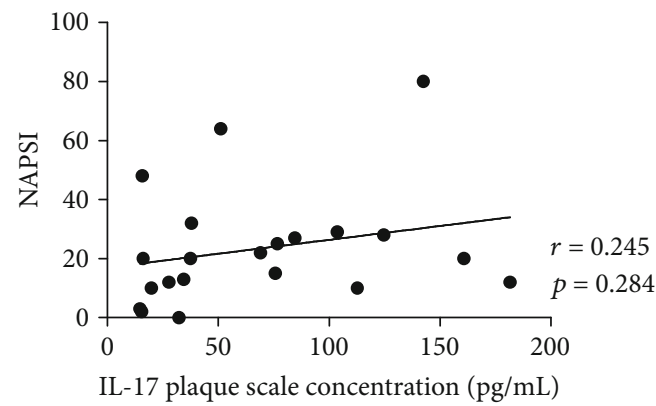

(e)

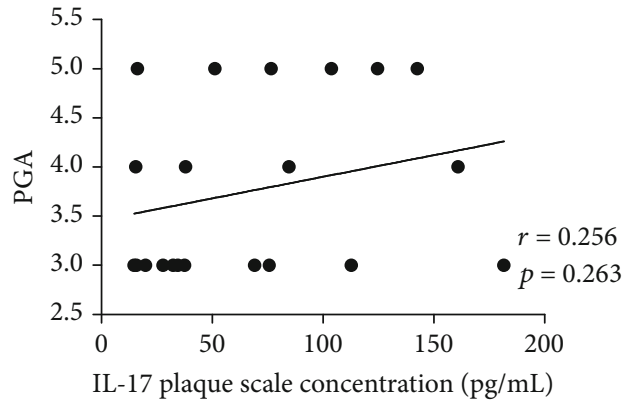

(b)

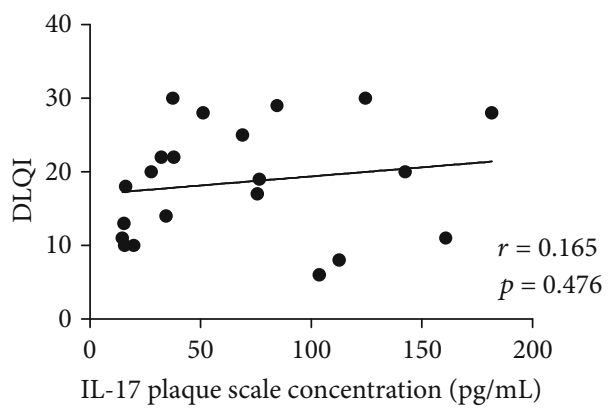

(d)

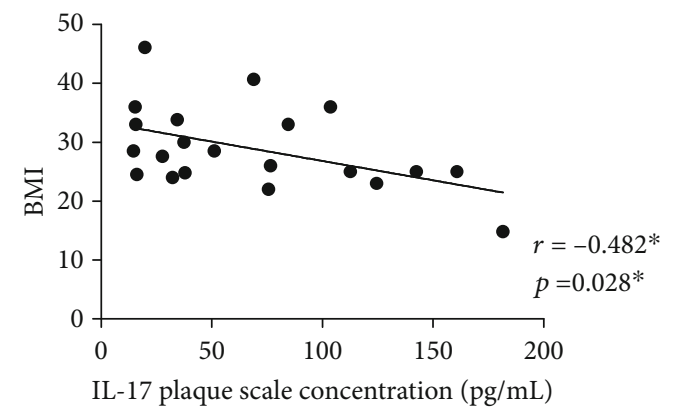

(f)

Figure 2: The correlation between IL-17 plaque scale concentration and clinical features and disease severity in psoriatic patients; * statistically significant correlation.

similar to the results presented by Bardazzi et al. In that study, overweight patients were accounted for $40 \%$ of enrolled patients, and obesity was observed in $42 \%$ of patients [46]. They did not show statistically significant differences between PASI in selected groups of patients either. However, it was observed that in obese patients PASI was higher $(32.36 \pm$ 12.79) comparing to the normal and overweight patients with PASI $19.63 \pm 9.17$. We did not have similar observations. In the psoriatic patients, BMI was higher than in the control group, and it was a statistically significant difference. Many studies including very big numbers of psoriatic patients demonstrated that the risk of severe psoriasis in an overweight or obese population was higher than in normalweight people $[5,47-50]$. The meta-analysis of 16 observational studies including 201,831 patients with psoriasis demonstrated that compared with individuals from the general population, psoriatic patients, especially with severe psoriasis, are at significantly higher odds of obesity $[5,51]$. However, according to current epidemiological evidence, it is impossible to establish which comes first, psoriasis or obesity. Evidence strongly suggests that obesity is an independent risk factor for psoriasis [5].

The main limitation of our study is the use of BMI for obesity assessment. BMI is used extensively in research and clinical practice; however, it could have limited diagnostic performance due to its inability to discriminate between fat and lean mass [52-56]. Whereas the body fat \% (BF\%) has been associated with some health problems like cardiovascular diseases [53]. BMI fails to indicate the severity of the comorbidities [54]. In the study of Romero-Corral A. et al., bioelectrical impedance was used to assess body fatness. They found that using BMI as a marker of obesity, they misclassified $\geq 50 \%$ of patients with excess body fat as being normal or just overweight [53]. In a recent study, Galluzzo et al. also indicated that bioelectrical impedance analysis is able to identify obese psoriatic patients in the group of normalweight patients detected by using BMI alone and suggested screening for body fat distribution in psoriatic patients with 
a normal or slightly elevated BMI, since this might be crucial to identify patients at risk of obesity-related diseases, like hyperlipidemia, coronary artery disease, hypertension, and diabetes, and to enhance prevention strategies [52]. Galluzo et al. found also that the values of adipose tissue were not correlated with psoriasis severity, which is similar to our results of BMI/PASI correlations [52]. Other methods which can be helpful in $\mathrm{BF} \%$ measurement are hydrostatic weighting, energy-dual X-ray absorptiometry, and air displacement plethysmography $[53,57]$. We are going to perform an additional $\mathrm{BF} \%$ evaluation in future studies.

The link between psoriasis and obesity can be explained with new knowledge about white adipose tissue which is an essential endocrine organ secreting a wide range of soluble mediators involved in immunity, inflammation, and metabolic and appetite regulation $[5,58,59]$. The soluble mediators possess proinflammatory actions and can contribute to the low-grade inflammatory state in obese individuals [58]. There are also studies suggesting that adiposity may lead to the induction of T-helper 17 cells (Th17) which take part in the involvement in the pathogenesis of autoimmune diseases including psoriasis $[5,60]$.

Correlations between IL-17, psoriasis, and increased adiposity were poorly investigated so far. Recent studies have observed that serum levels of IL-17 are significantly higher in obese subjects compared with controls. In particular, a study based on obese women underlines a role for IL-17 and IL-23 as potential markers of the inflammatory syndrome that characterizes obesity [61-63]. We did not observe any statistically significant correlation between IL-17A serum concentration and BMI. However, in patients with higher BMI, the scale concentration of IL-17A was decreased $(p=0.028, r=-0.482)$.

IL-17 belongs to a family of proinflammatory cytokines, and its role in the pathogenesis of obesity is as important as that of IL-1, IL-6, IFN, or TNF-alpha [17, 64]. Obesity positively correlated with both IL-17 expression and disease severity in IL-17-driven inflammatory mouse models $[65,66]$. Pini and Fantuzzi demonstrated an increased concentration of IL$17 \mathrm{~A}$ in obese mice in provoked acute inflammation [16]. Adipocytes and macrophages in visceral adipose tissue produce IL-6 which activates intracellular STAT3 and retinoid-related orphan receptors, increasing differentiation of the Th17 cells [17]. Recently, it was demonstrated that TGF-beta is engaged in the enhancement and mediation of this process [67]. An increased serum concentration of amyloid $\mathrm{A}$ in inflammation associated with obesity influences the differentiation of Th17 lines [17]. TNF-alpha production is also increased in obesity and correlates with the IL-17 production [68].

On the other hand, IL-17 inhibits adipogenesis, reduces lipid and glucose uptake acting on both preadipocytes and adipocytes $[61,69,70]$. IL-17 deficiency increases dietinduced obesity and accelerates adipose tissue accumulation [15]. IL-17 modifies also the expression of adipogenic transcription factors [15]. An increased IL-17 secretion results in increased activity of cyclooxygenase-2, therefore increased prostaglandin E2 production, and prostaglandin E2 inhibits differentiation of adipocytes. Increased IL-17 concentration is also responsible for lipolysis in adipocytes [64].

\section{Conclusions}

The group of male patients with severe psoriasis presented in this study has BMI higher than in the control group. $76 \%$ of patients presented BMI higher than normal. Our study, similar to other publications, confirms that overweight is a problem among psoriatic patients. The role of IL-17 in the psoriasis pathophysiology is recognized. A significant positive correlation between the IL-17 serum concentrations as well as IL-17 scale concentrations, and psoriasis severity indicates that IL-17 can be suggested as the marker of the disease severity. However, it remains an unresolved question about the influence of IL-17 on overweight and obesity in psoriatic patients. In patients with higher BMI, the scale concentration of IL-17A was decreased, which can be significant, but it could also be an unimportant result since the small group of patients. Studies should be extended to check this correlation. The studies on animal models suggest the importance of IL-17 in the obesity pathophysiology. That is why more data from human studies can be crucial for understanding the relationship between IL-17, psoriasis, and obesity.

\section{Data Availability}

The data used to support the findings of this study are available from the corresponding author upon request.

\section{Ethical Approval}

All procedures performed in the study were in accordance with the ethical standards of the institutional research committee and with the 1964 Helsinki declaration and its later amendments or comparable ethical standards.

\section{Conflicts of Interest}

The authors declare no competing interests.

\section{Authors' Contributions}

AMS, JB, and GC conceived the idea for the study. AMS, JB, and MK contributed to the design of the research. AMS, JB, and $\mathrm{MK}$ were involved in data collection. DR performed the statistical analysis. AMS, JB, and GC analyzed the data. GC coordinated funding for the project. AMS, JB, GC, and DK made the final revision of the manuscript. All authors edited and approved the final version of the manuscript.

\section{Acknowledgments}

This work was supported by grant no. 164 of the Medical University of Lublin, Poland.

\section{References}

[1] R. Parisi, D. P. Symmons, C. E. Griffiths, D. M. Ashcroft, and Identification and Management of Psoriasis and Associated ComorbidiTy (IMPACT) project team, "Global epidemiology of psoriasis: a systematic review of incidence and prevalence," The Journal of Investigative Dermatology, vol. 133, no. 2, pp. 377-385, 2013. 
[2] J. Baliwag, D. H. Barnes, and A. Johnston, "Cytokines in psoriasis," Cytokine, vol. 73, no. 2, pp. 342-350, 2015.

[3] B. J. Nickoloff and F. O. Nestle, "Recent insights into the immunopathogenesis of psoriasis provide new therapeutic opportunities," The Journal of Clinical Investigation, vol. 113, no. 12, pp. 1664-1675, 2004.

[4] J. Takeshita, S. Grewal, S. M. Langan et al., "Psoriasis and comorbid diseases: epidemiology," Journal of the American Academy of Dermatology, vol. 76, no. 3, pp. 377-390, 2017.

[5] P. Jensen and L. Skov, "Psoriasis and obesity," Dermatology, vol. 232, no. 6, pp. 633-639, 2017.

[6] A. Di Cesare, P. Di Meglio, and F. O. Nestle, "The IL-23/Th17 axis in the immunopathogenesis of psoriasis," The Journal of Investigative Dermatology, vol. 129, no. 6, pp. 1339-1350, 2009.

[7] A. Owczarczyk-Saczonek and W. Placek, "Interleukin-17 as a factor linking the pathogenesis of psoriasis with metabolic disorders," International Journal of Dermatology, vol. 56, no. 3, pp. 260-268, 2017.

[8] J. B. Golden, T. S. McCormick, and N. L. Ward, "IL-17 in psoriasis: implications for therapy and cardiovascular co-morbidities," Cytokine, vol. 62, no. 2, pp. 195-201, 2013.

[9] C. Johansen, P. A. Usher, R. B. Kjellerup, D. Lundsgaard, L. Iversen, and K. Kragballe, "Characterization of the interleukin-17 isoforms and receptors in lesional psoriatic skin," The British Journal of Dermatology, vol. 160, no. 2, pp. 319-324, 2009.

[10] R. R. M. C. Keijsers, I. Joosten, P. E. J. van Erp, H. J. P. M. Koenen, and P. C. M. van de Kerkhof, "Cellular sources of IL-17 in psoriasis: a paradigm shift?," Experimental Dermatology, vol. 23, no. 11, pp. 799-803, 2014.

[11] A. Wasilewska, M. Winiarska, M. Olszewska, and L. Rudnicka, "Interleukin-17 inhibitors. A new era in treatment of psoriasis and other skin diseases," Advances in Dermatology and Allergology, vol. 33, no. 4, pp. 247-252, 2016.

[12] A. W. Armstrong, S. V. Voyles, E. J. Armstrong, E. N. Fuller, and J. C. Rutledge, "A tale of two plaques: convergent mechanisms of T-cell-mediated inflammation in psoriasis and atherosclerosis," Experimental Dermatology, vol. 20, no. 7, pp. 544-549, 2011.

[13] A. Michalak-Stoma, J. Bartosińska, M. Kowal, M. JuszkiewiczBorowiec, A. Gerkowicz, and G. Chodorowska, "Serum levels of selected Th17 and Th22 cytokines in psoriatic patients," Disease Markers, vol. 35, no. 6, 631 pages, 2013.

[14] M. Sumarac-Dumanovic, D. Jeremic, A. Pantovic et al., "Therapeutic improvement of glucoregulation in newly diagnosed type 2 diabetes patients is associated with a reduction of IL17 levels," Immunobiology, vol. 218, no. 8, pp. 1113-1118, 2013.

[15] M. Ahmed and S. L. Gaffen, "IL-17 inhibits adipogenesis in part via $\mathrm{C} / \mathrm{EBP} \alpha, \operatorname{PPAR} \gamma$ and Krüppel-like factors," Cytokine, vol. 61, no. 3, pp. 898-905, 2013.

[16] M. Pini and G. Fantuzzi, "Enhanced production of IL-17A during zymosan-induced peritonitis in obese mice," Journal of Leukocyte Biology, vol. 87, no. 1, pp. 51-58, 2010.

[17] S. Winer, G. Paltser, Y. Chan et al., "Obesity predisposes to Th17 bias," European Journal of Immunology, vol. 39, no. 9, pp. 2629-2635, 2009.

[18] M. Diani, G. Altomare, and E. Reali, "T cell responses in psoriasis and psoriatic arthritis," Autoimmunity Reviews, vol. 14, no. 4, pp. 286-292, 2015.
[19] M. B. M. Teunissen, J. D. Bos, C. W. Koomen, R. de Waal Malefyt, and E. A. Wierenga, "Interleukin-17 and interferon- $\gamma$ synergize in the enhancement of proinflammatory cytokine production by human keratinocytes," The Journal of Investigative Dermatology, vol. 111, no. 4, pp. 645-649, 1998.

[20] C. Albanesi, A. Cavani, and G. Girolomoni, "IL-17 is produced by nickel-specific $\mathrm{T}$ lymphocytes and regulates ICAM-1 expression and chemokine production in human keratinocytes: synergistic or antagonist effects with IFN- $\gamma$ and TNF$\alpha$," Journal of Immunology, vol. 162, pp. 494-502, 1999.

[21] J. Witowski, K. Książek, and A. Jörres, "Interleukin-17: a mediator of inflammatory responses," Cellular and Molecular Life Sciences, vol. 61, no. 5, pp. 567-579, 2004.

[22] A. T. Pietrzak, A. Zalewska, G. Chodorowska et al., "Cytokines and anticytokines in psoriasis," Clinica Chimica Acta, vol. 394, no. 1-2, pp. 7-21, 2008.

[23] E. G. Harper, C. Guo, H. Rizzo et al., “Th17 cytokines stimulate CCL20 expression in keratinocytes in vitro and in vivo: implications for psoriasis pathogenesis," The Journal of Investigative Dermatology, vol. 129, no. 9, pp. 2175-2183, 2009.

[24] N. J. Wilson, K. Boniface, J. R. Chan et al., "Development, cytokine profile and function of human interleukin 17-producing helper T cells," Nature Immunology, vol. 8, no. 9, pp. 950957, 2007.

[25] S. Kagami, H. L. Rizzo, J. J. Lee, Y. Koguchi, and A. Blauvelt, "Circulating Th17, Th22, and Th1 cells are increased in psoriasis," The Journal of Investigative Dermatology, vol. 130, no. 5, pp. 1373-1383, 2010.

[26] S. Matsushita and T. Higashi, "Human Th17 cell clones and natural immune responses," Allergology International, vol. 57, no. 2, pp. 135-140, 2008.

[27] M. A. Lowes, T. Kikuchi, J. Fuentes-Duculan et al., "Psoriasis vulgaris lesions contain discrete populations of Th1 and Th17 T cells," The Journal of Investigative Dermatology, vol. 128, no. 5, pp. 1207-1211, 2008.

[28] H. Takahashi, H. Tsuji, Y. Hashimoto, A. Ishida-Yamamoto, and H. Iizuka, "Serum cytokines and growth factor levels in Japanese patients with psoriasis," Clinical and Experimental Dermatology, vol. 35, no. 6, pp. 645-649, 2010.

[29] H. A. El-Moaty Zaher, M. H. El-Komy, R. A. Hegazy, H. A. Mohamed El Khashab, and H. H. Ahmed, "Assessment of interleukin-17 and vitamin D serum levels in psoriatic patients," Journal of the American Academy of Dermatology, vol. 69, no. 5, pp. 840-842, 2013.

[30] P. S. S. de Oliveira, P. R. G. Cardoso, E. V. de Andrade Lima et al., "IL-17A, IL-22, IL-6, and IL-21 serum levels in plaquetype psoriasis in Brazilian patients," Mediators of Inflammation, vol. 2015, Article ID 819149, 5 pages, 2015.

[31] M. Caproni, E. Antiga, L. Melani, W. Volpi, E. del Bianco, and P. Fabbri, "Serum levels of IL-17 and IL-22 are reduced by etanercept, but not by acitretin, in patients with psoriasis: a randomized-controlled trial," Journal of Clinical Immunology, vol. 29, no. 2, pp. 210-214, 2009.

[32] M. Suárez-Fariñas, K. Li, J. Fuentes-Duculan, K. Hayden, C. Brodmerkel, and J. G. Krueger, "Expanding the psoriasis disease profile: interrogation of the skin and serum of patients with moderate-to-severe psoriasis," The Journal of Investigative Dermatology, vol. 132, no. 11, pp. 2552-2564, 2012.

[33] S. Bajaj, R. K. Gautam, A. Khurana, P. Arora, and N. Sharma, "Effect of narrow band ultraviolet B phototherapy on T helper 17 cell specific cytokines (interleukins-17, 22 and 23) in 
psoriasis vulgaris," The Journal of Dermatological Treatment, vol. 28, no. 1, pp. 14-17, 2017.

[34] O. Arican, M. Aral, S. Sasmaz, and P. Ciragil, "Serum levels of TNF- $\alpha$, IFN- $\gamma$, IL-6, IL-8, IL-12, IL-17, and IL-18 in patients with active psoriasis and correlation with disease severity," Mediators of Inflammation, vol. 2005, no. 5, 279 pages, 2005.

[35] Y. B. Choe, Y. J. Hwang, H. J. Hahn et al., “A comparison of serum inflammatory cytokines according to phenotype in patients with psoriasis," The British Journal of Dermatology, vol. 167, no. 4, pp. 762-767, 2012.

[36] A. Kyriakou, A. Patsatsi, T. A. Vyzantiadis, and D. Sotiriadis, "Serum levels of TNF- $\alpha$, IL-12/23 p40, and IL-17 in psoriatic patients with and without nail psoriasis: a cross-sectional study," Scientific World Journal, vol. 2014, article 508178, pp. 1-5, 2014.

[37] I. Flisiak, M. Szterling-Jaworowska, A. Baran, and M. Rogalska-Taranta, "Effect of psoriasis activity on epidermal growth factor (EGF) and the concentration of soluble EGF receptor in serum and plaque scales," Clinical and Experimental Dermatology, vol. 39, no. 4, pp. 461-467, 2014.

[38] I. Flisiak, P. Zaniewski, M. Rogalska, H. Myśliwiec, J. Jaroszewicz, and B. Chodynicka, "Effect of psoriasis activity on VEGF and its soluble receptors concentrations in serum and plaque scales," Cytokine, vol. 52, no. 3, pp. 225-229, 2010.

[39] I. Flisiak, A. Klepacki, and B. Chodynicka, "Plasma and scales levels of interleukin 18 in comparison with other possible clinical and laboratory biomarkers of psoriasis activity," Biomarkers, vol. 11, no. 2, pp. 194-200, 2008.

[40] I. Deeva, S. Mariani, C. de Luca et al., "Wide-spectrum profile of inflammatory mediators in the plasma and scales of patients with psoriatic disease," Cytokine, vol. 49, no. 2, pp. 163-170, 2010.

[41] S. B. Yilmaz, N. Cicek, M. Coskun, O. Yegin, and E. Alpsoy, "Serum and tissue levels of IL-17 in different clinical subtypes of psoriasis," Archives of Dermatological Research, vol. 304, no. 6, pp. 465-469, 2012.

[42] A. M. Lin, C. J. Rubin, R. Khandpur et al., "Mast cells and neutrophils release IL-17 through extracellular trap formation in psoriasis," Journal of Immunology, vol. 187, no. 1, pp. 490500, 2011.

[43] L. Senra, R. Stalder, D. Alvarez Martinez, C. Chizzolini, W. H. Boehncke, and N. C. Brembilla, "Keratinocyte-derived IL-17E contributes to inflammation in psoriasis," The Journal of Investigative Dermatology, vol. 136, no. 10, pp. 1970-1980, 2016.

[44] N. C. Brembilla, L. Senra, and W. H. Boehncke, "The IL-17 family of cytokines in psoriasis: IL-17A and beyond," Frontiers in Immunology, vol. 9, p. 1682, 2018.

[45] K. Reich, K. A. Papp, R. T. Matheson et al., "Evidence that a neutrophil-keratinocyte crosstalk is an early target of IL-17A inhibition in psoriasis," Experimental Dermatology, vol. 24, no. 7, pp. 529-535, 2015.

[46] F. Bardazzi, R. Balestri, E. Baldi, A. Antonucci, S. de Tommaso, and A. Patrizi, "Correlation between BMI and PASI in patients affected by moderate to severe psoriasis undergoing biological therapy," Dermatologic Therapy, vol. 23, Supplement 1, pp. S14-S19, 2010.

[47] T. Henseler and E. Christophers, "Disease concomitance in psoriasis," Journal of the American Academy of Dermatology, vol. 32, no. 6, pp. 982-986, 1995.

[48] L. Naldi, L. Chatenoud, D. Linder et al., "Cigarette smoking, body mass index, and stressful life events as risk factors for psoriasis: results from an Italian case-control study," The Journal of Investigative Dermatology, vol. 125, no. 1, pp. 61-67, 2005.

[49] A. L. Neimann, D. B. Shin, X. Wang, D. J. Margolis, A. B. Troxel, and J. M. Gelfand, "Prevalence of cardiovascular risk factors in patients with psoriasis," Journal of the American Academy of Dermatology, vol. 55, no. 5, pp. 829-835, 2006.

[50] A. D. Cohen, M. Sherf, L. Vidavsky, D. A. Vardy, J. Shapiro, and J. Meyerovitch, "Association between psoriasis and the metabolic syndrome," Dermatology, vol. 216, no. 2, pp. 152155,2008

[51] A. W. Armstrong, C. T. Harskamp, and E. J. Armstrong, "The association between psoriasis and obesity: a systematic review and meta- analysis of observational studies," Nutrition \& Diabetes, vol. 2, no. 12, article e54, 2012.

[52] M. Galluzzo, M. Talamonti, F. Perino et al., "Bioelectrical impedance analysis to define an excess of body fat: evaluation in patients with psoriasis," The Journal of Dermatological Treatment, vol. 28, no. 4, pp. 299-303, 2016.

[53] A. Romero-Corral, V. K. Somers, J. Sierra-Johnson et al., "Accuracy of body mass index in diagnosing obesity in the adult general population," International Journal of Obesity, vol. 32, no. 6, pp. 959-966, 2008.

[54] W. J. Pories, L. G. Dohm, and C. J. Mansfield, "Beyond the BMI: the search for better guidelines for bariatric surgery," Obesity, vol. 18, no. 5, pp. 865-871, 2010.

[55] T. R. Fleming and D. DeMets, "Surrogate end points in clinical trials: are we being misled?," Annals of Internal Medicine, vol. 125, no. 7, pp. 605-613, 1996.

[56] K. R. Segal, M. van Loan, P. I. Fitzgerald, J. A. Hodgdon, and T. B. van Itallie, "Lean body mass estimation by bioelectrical impedance analysis: a four-site cross-validation study," The American Journal of Clinical Nutrition, vol. 47, no. 1, pp. 714, 1988.

[57] A. A. Hedley, C. L. Ogden, C. L. Johnson, M. D. Carroll, L. R. Curtin, and K. M. Flegal, "Prevalence of overweight and obesity among US children, adolescents, and adults, 1999-2002," JAMA, vol. 291, no. 23, pp. 2847-2850, 2004.

[58] H. Cao, "Adipocytokines in obesity and metabolic disease," The Journal of Endocrinology, vol. 220, no. 2, pp. T47-T59, 2014.

[59] R. Gómez, J. Conde, M. Scotece, J. J. Gómez-Reino, F. Lago, and O. Gualillo, "What's new in our understanding of the role of adipokines in rheumatic diseases?," Nature Reviews Rheumatology, vol. 7, no. 9, pp. 528-536, 2011.

[60] M. Versini, P. Y. Jeandel, E. Rosenthal, and Y. Shoenfeld, "Obesity in autoimmune diseases: not a passive bystander," Autoimmunity Reviews, vol. 13, no. 9, pp. 981-1000, 2014.

[61] F. Lago, C. Dieguez, J. Gómez-Reino, and O. Gualillo, “The emerging role of adipokines as mediators of inflammation and immune responses," Cytokine \& Growth Factor Reviews, vol. 18 , no. 3-4, pp. 313-325, 2007.

[62] M. Sumarac-Dumanovic, D. Stevanovic, A. Ljubic et al., "Increased activity of interleukin-23/interleukin-17 proinflammatory axis in obese women," International Journal of Obesity, vol. 33, no. 1, pp. 151-156, 2009.

[63] M. Granata, E. Skarmoutsou, C. Trovato, G. A. Rossi, M. C. Mazzarino, and F. D'Amico, "Obesity, type 1 diabetes, and psoriasis: an autoimmune triple flip," Pathobiology, vol. 84, no. 2, pp. 71-79, 2017. 
[64] J. H. Shin, D. W. Shin, and M. Noh, "Interleukin-17A inhibits adipocyte differentiation in human mesenchymal stem cells and regulates pro-inflammatory responses in adipocytes," Biochemical Pharmacology, vol. 77, no. 12, pp. 1835-1844, 2009.

[65] A. Chiricozzi, A. Raimondo, S. Lembo et al., "Crosstalk between skin inflammation and adipose tissue-derived products: pathogenic evidence linking psoriasis to increased adiposity," Expert Review of Clinical Immunology, vol. 12, no. 12, pp. 1299-1308, 2016.

[66] B. B. Davidovici, N. Sattar, P. C. Jörg et al., "Psoriasis and systemic inflammatory diseases: potential mechanistic links between skin disease and co-morbid conditions," The Journal of Investigative Dermatology, vol. 130, no. 7, pp. 1785-1796, 2010.

[67] T. Gislette and J. Chen, "The possible role of IL-17 in obesityassociated cancer," Scientific World Journal, vol. 10, pp. 22652271, 2010.

[68] K. A. Charles, H. Kulbe, R. Soper et al., "The tumor-promoting actions of TNF- $\alpha$ involve TNFR1 and IL-17 in ovarian cancer in mice and humans," The Journal of Clinical Investigation, vol. 119, no. 10, pp. 3011-3023, 2009.

[69] L. A. Zúñiga, W. J. Shen, B. Joyce-Shaikh et al., "IL-17 regulates adipogenesis, glucose homeostasis, and obesity," Journal of Immunology, vol. 185, no. 11, pp. 6947-6959, 2010.

[70] Z. Wang, L. Yang, Y. Jiang et al., "High fat diet induces formation of spontaneous liposarcoma in mouse adipose tissue with overexpression of interleukin 22," PLoS One, vol. 6, no. 8, article e23737, 2011. 